pected to consist of liquid phase only. The specimen was then furnace cooled. A section through the solidified specimens showed two types of structures. The surface layer, shown in Fig. 8a, consists of primary $\beta$ surrounded by a fine structure of $\beta$ and WC. The center of the specimen, shown in Fig. 8b, also shows primary $\beta$ but now surrounded by $\eta-\beta$ eutectic and numerous graphite flakes. The condition in the furnace was only slightly carburizing, if at all. The alundum crucible was enclosed in a graphite crucible, which was completely packed in norblack. The cooling rate on the surface of the specimen is expected to be faster than inside. The surface structure is in accordance with the metastable diagram. During the cooling from the liquid state the precipitation of $\beta$ starts first and during subsequent cooling simultaneous precipitation of $\mathrm{WC}$ and $\beta$ takes place. The composition of the specimen is such that all liquid is consumed before the eutectic temperature $1298^{\circ} \mathrm{C}$ has been reached.

The structure of the specimen core, apparently cooled slower, cannot be explained by means of the metastable diagram, which has no $\eta$-graphite equilibrium. Apparently the core has approached true equilibrium conditions more closely and thus the combination $\mathrm{C}_{0}-\eta$-graphite is the stable one. It will be noted that the composition of the specimen was not changed. The free graphite amounts to the difference between the carbon contents of WC and $\eta$.

\section{Tentative Model of Stable Diagram W-Co-C}

A stable system may be developed from the metastable by omitting the ternary transition at $1357^{\circ} \mathrm{C}$. Above this temperature the stable and the metastable diagrams are essentially the same. In the stable system the ternary transition:

$$
\text { Liquid }+\mathrm{WC}=\eta+\mathrm{C}
$$

produces the $\eta$-graphite equilibrium.

At a lower temperature a eutectic reaction:

$$
\text { Liquid }=\beta+\eta+\mathrm{C}
$$

produces the three phase field $\beta-\eta$-graphite. $\dagger$

$\dagger$ The temperature of this eutectic reaction was not revealed by the thermal analyses described. Apparently the thermocouple promen so that no $n$ phase was formed from the center of the speciperature of the eutectic reaction in the stable system is lower than in the metastable system.

A model of the stable equilibrium diagram $\mathrm{W}-\mathrm{Co}-$ $\mathrm{C}$ is illustrated in Fig. 9.

The characteristic feature of the metastable diagram is the two-phase field $\beta$-WC, which extends across the diagram. The cemented carbides should

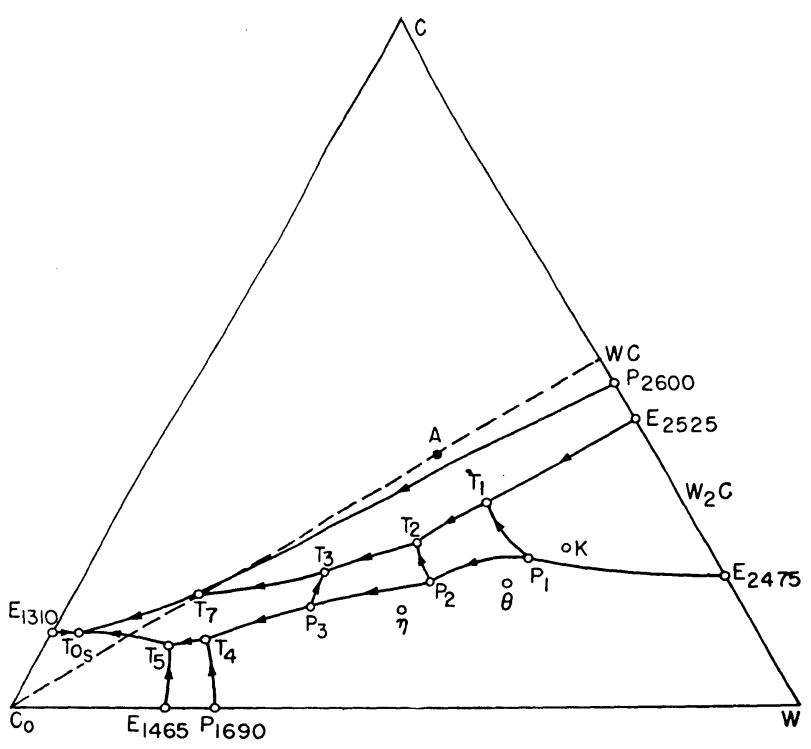

Fig. 9-Stable equilibrium diagram of W-Co-C. Representation by basal projection. The reactions $P_{1}$ to $T_{5}$ are the same as in Fig. 4. $T_{7}$ - Liquid $+W C=\eta+$ graphite. $T_{0_{s}}$-Liquid $=\beta+\eta+$ graphite.

have this structure. In the stable system this important two-phase equilibrium is destroyed. From the viewpoint of technical applications it is clear that the stable equilibrium is most undesirable. Therefore slow cooling rates from the sintering temperatures must be avoided.

\section{Acknowledgment}

Part of this work was sponsored by the Ordnance Dept. of the United States Army, Contracts No. W19-020-ORD-6489 and No. DA-19-020-ORD-10, under the technical supervision of the Watertown Arsenal Laboratory. Permission to publish the results is gratefully acknowledged.

\section{References}

${ }^{1}$ V. Adelskold, A. Sundelin, and A. Westgren: Ztsch. anorg. allgem. Chem. (1933) 212, p. 401.

${ }^{2}$ E. J. Sandford and E. M. Trent: Symposium on Powder Metallurgy. Iron and Steel Inst. Special Report 38, (1947) p. 84.

${ }^{\mathbf{3}}$ E. N. Kislyokova: Zhur, Fiz. Khim. (1943) 17, p. 108.

${ }^{4}$ S. Takeda: Technol. Repts. Tohoku Imp. Univ. (1931) 9, pp. 483, 627; and (1931) 10, p. 42.

${ }^{5}$ L. L. Wyman and F. C. Kelley: Trans. AIME (1931) 93, p. 208.

${ }^{6}$ A. Westgren: Jernkontorets Ann. (1933) 11\%, p. 1.

${ }^{7}$ L. D. Brownlee: Unpublished Report, Vickers Electrical Co. Ltd., Manchester, England.

\title{
Technical Note Strain Sensitivity of Commercial Purity Titanium
}

\section{by James L. Wyatt}

$\mathrm{T}$ HE strain sensitivity, $K$, a property of metals defined as the unit change in electrical resistance per unit strain, was measured for commercial purity titanium wire to determine its usefulness as a strain gage material. A Kelvin double bridge, accurate to $0.000001 \mathrm{ohm}$, was used to make measurements from 0 to 1 pct total strain. A positive

J. L. WYATT, Junior Member AIME, is National Lead Co. Fellow, Massachusetts Institute of Technology, Cambridge, Mass. TN 128E. Manuscript, April 29, 1952; revised, Aug. 5, 1952. value of 0.17 for $K$ was found. This compares with 2.15 for constantan and 3.5 for cold-worked invar, two of the more common strain gage materials.

The effect of temperature also was determined. It was found that a change in temperature of $30^{\circ} \mathrm{F}$ caused the same resistance change as 1 pct strain. It is therefore concluded that titanium would have utility as a strain gage only if the thermal fluctuations in the specimen could be controlled to a high degree and in applications of very large total strain. 